2013-08-07

Re-placing food: Place, embeddedness and local food

\author{
Willis, Katharine S.
}

http://hdl.handle.net/10026.1/4209

\title{
MIT Press
}

All content in PEARL is protected by copyright law. Author manuscripts are made available in accordance with publisher policies. Please cite only the published version using the details provided on the item record or document. In the absence of an open licence (e.g. Creative Commons), permissions for further reuse of content should be sought from the publisher or author. 


\title{
9 Re-placing Food: Place, Embeddedness, and Local Food
}

\author{
Katharine S. Willis, Katharina Frosch, and Mirjam Struppek
}

We live in a digital, networked society where immaterial transactions frame many aspects of our everyday life. But in an Internet of Things, our products and artifacts still have material presence: they have to be somewhere; they need to be physically displaced to arrive somewhere else; they cannot be easily duplicated; and they have a life cycle. All things that we consume need to travel from the place they are produced to the place in which they will be consumed. This process may cover a simple few feet or may involve thousands of miles and many weeks. In our current urbanized and globalized marketplace, food is often transported an extremely long distance from its origin to the place where it is sold. There has been some attempt to quantify the way in which food is part of a global marketplace through the introduction of the concept of "food miles" (Paxton 1994). This measures the distance food is transported from the time of its production until it reaches the market. The sheer distance for many items commonly available in supermarkets in the developed world underlines the disembedded nature of a globalized food system that creates a "placeless foodscape" (Ilbery and Kneafsey 2000, 319). As Ulrich Oltersdorf and Kurt Gedrich point out, "the place in which the food is produced and the place in which a person lives constructs less and less the framework for the food someone consumes" $(2001,66)$.

A growing resistance to this globalized food marketplace is seen as one of the reasons for the rise in interest in locally sourced food. This trend advocates closer connections between producers and consumers both in terms of spatial distance and personal networks. Such direct agricultural markets privilege locality and seasonality over distance and durability (Friedmann 1993). However, there is also a growing movement to take this a step further and to reconnect the person with food at the most basic level. In this way "localism provides a defensive position against the disempowering and homogenizing effects of globalisation" (Allen 2004, 169). Yet, this is complicated by the fact that there are many complex and conflicting meanings tied up in the discourse of the "local" with respect to food (Allen 2004). According to Leslie Duram and Lydia Oberholtzer, "although local foods are increasingly gaining the public's attention, there is no clear geographical delineation for 'local'" $(2010,2)$. Indeed, ideas of what 
constitutes local are both culturally and geographically situated. In the United States a study found that geographical topologies helped to shape ideas of what was local, such that urban density on the East Coast may mean that "local" in Washington, DC, is defined as being within a hundred miles from the city, whereas in Iowa "local" food is defined as that which has been made or produced within the state boundary (Duram and Oberholtzer 2010, 2). In Germany, local food is generally accepted as food produced in the "region," which is either a county or a topographic region. In a survey, 40 percent understood the region as the county in which they lived, whereas 14 percent saw it as the geographical region (ZMP 2003). In the German context, the term regional is also closely linked to idea of "cradle to grave," where the life cycle of the product is contained within a specific area (Kindermann 1997). Thus a clear definition or common cultural understanding of what is local can never be achieved because it is spatially and culturally embedded in the context of its use.

Consumers of local food can be defined by a shared wish to strengthen a connection to a commons, to land and landscape, to people and place. According to actor-network theory, strategies that support relocalization are based on building production-consumption networks around specific meanings and objectives. The success of such strategies depends on its capacity to align actors along shared axes of meaning as the condition to coordinate their action (Latour 1987). In terms of the context of the market, farmers' markets work at achieving such a reconfiguration, since they seek to create an "immediate, personal and enacted in shared space" (Lyson and Green 1999, 137). Such direct market venues, which alongside farmers' markets also include community-supported agriculture and vegetable box schemes, create links between the farmer or producer and the consumer through simple everyday exchange. According to Clare Hinrichs (2000, 295), "direct agricultural markets promise human connection at the place where production and consumption of food converge." Embeddedness, in this sense of social connection, reciprocity, and trust, is often seen as the hallmark of direct agricultural markets. The social and spatial grounding of food in a local system enables and constrains production and consumption through its own unique characteristics (Hendrickson and Heffernan 2002). In direct counterpoint to a globalized food marketplace, embedded markets leave the supply of food open to local agency and change. It is at this scale that differentiated and discernible differences in the spatial and temporal experience are fundamental to the concept of local food.

In this chapter we will look at the emergence of an interest in re-localizing food systems. The "re-placing" of food can be seen not just as reconstructing relationships between consumer and producer, but as a way of people re-embedding their relationship with food within a sense of the spatial structure of their lives. We investigate this through two stages: first, we review of the concept of localism and food and how this constructs different relationships between people and place; second, we put this concept into context through a qualitative case study of the use of a German-based 
Web resource, www.mundraub.org. The mundraub.org website invites people to tag forgotten fruit trees on an interactive map and to locate existing trees that can be harvested. We will explore how the crowdsourced creation of a map-based resource documenting over five thousand fruit trees and wild edible plants can create a redefined sense of the local and re-embed food consumption within a local spatial setting. Interestingly, mundraub.org is widely used by urban dwellers and a large proportion of the map tags relate to urban and extra-urban tree sites, so this re-embedding should be seen within the context of a re-examination of the urban and its relationship with food.

\section{Scrumping, Foraging, Scrounging, and Collecting}

Farmers' markets, local co-ops, and vegetable box schemes represent the direct link between producer and consumer. It is for this reason that they can be seen as a fundamental basis for the local food movement. At the same time, a reemergence of other forms of local food sourcing is taking place, specifically foraging and scrumping. In these activities there is no person at the production end of the supply chain; instead, there is only the consumer, in direct relationship with the source of the food. Thus the consumer is also the farmer, in the sense of harvesting the food and preparing it for eating. In this way the natural world offers a significant counter to the idea of a market based on monetary exchange: wild flowers, trees, and herbs offer a free exchange, where ownership is ambiguous and rarely contested. The scrumping movement takes a wider approach to forming a relationship with the natural world and with the idea of "wild" food, one in which it is important to understand how the relationship with nature and the sourcing of food has shifted.

The website platform mundraub.org supports scrumping, and is primarily active in Germany (Frosch 2012). The German term "Mundraub" is grounded in that country's tradition of planting trees as a resource. For instance, up until the nineteenth century people were obliged by law to plant a fruit tree when they married (Krug 1808). Initially there was no law preventing commoners from helping themselves to the fruit, but in the build-up to World War II a law known as "Mundraub"1 was introduced, which roughly translates as "stealing from the mouth" (the closest translation of the practice is the English term "scrumping." ${ }^{2}$ ). The law made taking produce from these trees illegal. After the war, more trees were planted in East Germany due to a widespread fear of food shortages, and the Mundraub law was only withdrawn in 1975. But even now the harvesting of fruit in Germany is illegal unless the owner gives permission, and failure to get consent can potentially leave the individual liable to being prosecuted for theft.

This highlights an important and charged aspect of scrumping as an activity. There are effectively no fruit trees in Germany that are not owned: trees either belong to 
private persons or to the state, county, or local parish, depending on who owns the land where they grow. For this reason, scrumping is often regarded as a semi-illegal activity and equated with poaching. The practice is also culturally situated, with different connotations in different cultural contexts. In Germany and in the United Kingdom it is tolerated and a widely known practice, but scrumping is fairly unknown in the United States, where the nearest equivalent term is "rustling." In Sweden it is referred to as "palla," specifically meaning to steal fruit from trees in other people's gardens. The practice of scrumping has particular resonance in German society, however, which has a tradition of seeing the natural landscape as something that is not just passively there, but has the capacity for "giving." It is understood by many as restorative or healing, and recognized as a resource. For example, the German field titled "Naturheilkunde" (Naturotherapy) sees nature providing the opportunity and capacity to set free "bodily energy and spiritual forces which can instigate self-healing" (Brauchle 1935, 153), where one of the key practices is the consumption of raw food. Complementing this is the idea that the countryside and nature can offer healing through plants and natural medications, so that the rural world is traditionally seen as the "farmer's apothecary." Yet the current wider global progress toward supermarket food and shopping has meant that the necessary local knowledge about the qualities of particular plants or food is no longer a part of everyday life, particularly for the city dweller but also for rural residents. The revived interest in scrumping can be seen in the context of a desire to find ways of sourcing local food directly from the natural world.

The economist Avner Offer (1997) proposes a framework for an understanding of nonmarket exchange that introduces the idea of the "economy of regard." These transactions are usually referred to as "gifting" and take place in the context of nonmonetary reciprocity. The gift can be expensive or cheap, substantive or symbolic, but it is not costless. Here the value of the transaction is not measured quantitatively but in terms of "intrinsic benefits of social and personal interaction; from the satisfaction of regard" (Offer 1997, 450). Regard can take many forms, but at the very basic level "regard" is a grant of attention, underplayed by the motivation of the mutual benefit of sharing goods. This is important notion for the interpretation of the practices of scrumping, foraging, and scrounging, since regard in this context is not exchanged between two people but instead directly between some natural source of food and the potential consumer. The regard is then not a social regard between two humans but a direct reciprocity between the resource (which is seen as gifting or giving some fruit or herb) and the person (who harvests the fruit or herb for their consumption).

We now discuss a qualitative study of the use of the mundraub.org platform, and try to understand how concepts of localism and the corresponding relations of regard are constructed and practiced. 
PROPERTY OF MIT PRESS: FOR PROOFREADING AND INDEXING PURPOSES ONLY

Re-placing Food

\section{Case Study of Mundraub.org}

Mundraub.org creates a platform through which wild or forgotten fruit trees, as well as nut trees, herbs, or berries can be identified by one person or group, and then located and harvested by others, with an open-access interactive map. The mundraub.org platform is a simple map with tags that can be created by any user to add a food source categorized as fruits, nuts, berries, herbs, and gardens. Justin Buckley, Katharina Frosch (co-author of this chapter), Kai Gildhorn, Daniel Nielsen, and Mirco Meyer initiated the platform in 2009 following a canoe trip to the former East Germany, during which they noticed large numbers of forgotten fruit trees. It is a nonprofit site currently run by volunteers, and to date there have been over seven thousand five hundred tags created (status as of July 31, 2013), many of which denote multiple trees, orchards, and plants so that the individual tags represent a much larger number of trees and plants. A tag will list an entry according to a category and subcategory (e.g., fruit, apple) and the entry format prompts for a "who, where, what, how" description of the find that often includes a text description with directions to the location-see figure 9.1 for a sample tag. The site does not provide details such as GPS coordinates or use other location-based technology, and it is not currently available on a mobile device (though a mobile platform is planned for 2014).

Typical content is focused on the description of the fruit and a description of how to find the tree or bush. This is often augmented with other details, such as the taste of the fruit. There is an associated Facebook site, which has 4,762 members (status as of July 31, 2013). Typical entries peak in autumn and focus on identifying fruit types, sharing of recipes for preparing or preserving fruit, and general information about related events or projects nationally—see figure 9.2.

\section{Method}

We studied the use of mundraub.org using a range of methods. Initially we undertook a data-mining study of the mundraub.org website entries and also the parallel Facebook group site. The main qualitative analysis was through a series of semistructured interviews of approximately thirty minutes with eight mundraub users. We recruited eight mundraubers from Germany, mainly through an advertisement on the Facebook website. There were six men (Ola, Michael, Sebastian, Marco, Niko, and Karl) and two women (Simone and Danielle) with an age range from the twenties to sixties. None were paid for their participation and the interviews were undertaken in German (thus, any quotations in the following text are the authors' translations of the original response). The participants came from a range of urban and rural home locations and covered a range of mundraub.org experience. In selecting participants the aim was not to create the basis for statistical comparisons across different types of users and 


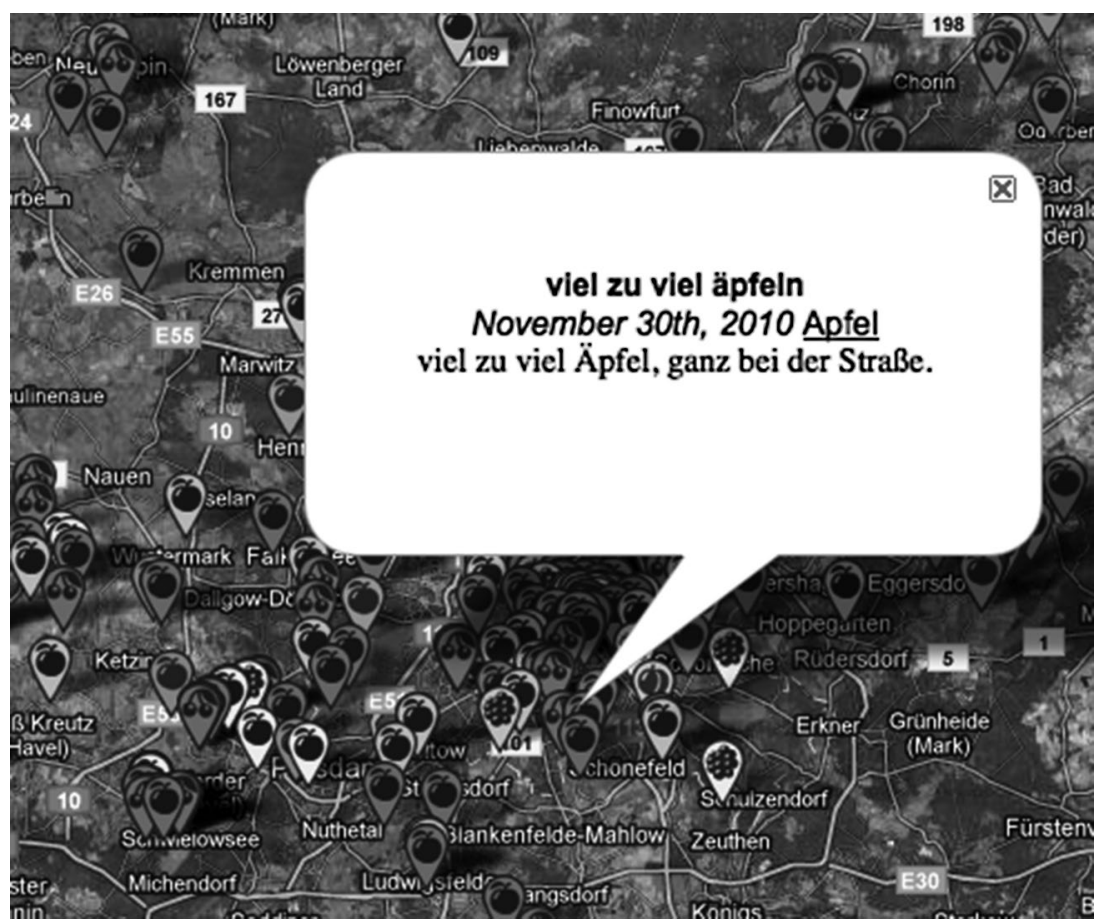

Figure 9.1

Mundraub tag in Berlin. Tag: "Far too many apples. Right on the road." Cibola comment: "Loads of apples, ideal for juice or apple sauce."

experience levels (which would not be appropriate with such a sample size). Rather, the aim was to provide an opportunity for issues particular to different types of users to be raised in the study.

\section{Findings}

In this section we present a subset of findings from the qualitative study. We organize our findings around the three different ways in which people use mundraub.org: first, the descriptions from the interviews of the individual experience of finding, tagging, and harvesting fruit; second, the characteristics of the tag; third, the way in which the Facebook site was used to share experience and document scrumping outcomes. We consider the findings in the context of how ideas of "locality" were practiced and how relations of regard were expressed and acted out.

The main common experience expressed by those interviewed was the way in which people started to develop a different awareness, understanding, and appreciation of what was local to them. This was almost always equated with "seeing" the place dif- 


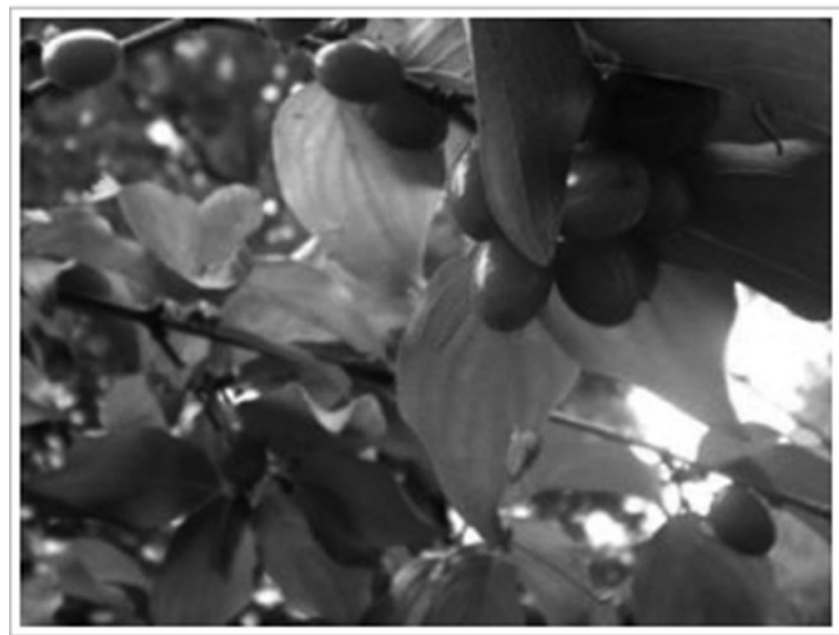

Like - Comment - Follow Post - August 2 at 12:09am

\section{5 people like this.}

Schamanca Sibylle-Silvia Helesic was für eine kirschensorte ist das?

August 2 at 4:54pm - Like

\section{Figure 9.2}

Facebook discussion around the identification of the fruit pictured in the image. (Schamanca, "What sort of cherry is this?" Answer, "They are cornel cherries? But not ripe yet!!")

ferently, but also related to the seasons and the change in their experience of time. The common aspect of the way the participants related to the fruit they had harvested was an interest in finding out about how to prepare and preserve it, which they found they needed to learn.

\section{Awareness}

Interviewees commented on how the use of the mundraub.org platform had opened their eyes to an awareness and identity with their local environment. This was independent of whether they were city or rural dwellers. They saw this in contrast to other inhabitants who "don't seem to know what there is in their local environment" (Ola). They also talked about the way in which both everyday and special journeys were somehow woven into the mundraub.org exploration. For example, one commented how "when I go walking I just look around" (Michael). Others described how a car trip was interrupted by the discovery of fruit trees along the road: "We were driving 
and we just saw all these trees so we stopped and gathered damsons" (Ola). Another described how his frequent train trips became opportunities to spot apple trees along the train tracks. The heightened awareness and practice of looking is underlined by one participant who described how:

I always try to move through the city with open eyes, and am always pleased when I find a tree with fruit somewhere. . . . This definitely changes my perception of the city. I associate certain places with certain trees and seasons. I also discover new areas of the city that otherwise I might never have been to. (Sebastian)

All of the interviewees referred to the practice of watching trees in their locality, and this being not just a one-off relationship of observation but a longer-term involvement with the tree location and a consequent sense of themselves being intertwined with the fruit tree places.

\section{Seasonality}

The practice of watching for what was happening both around them and in certain locations was finely linked with the seasons and thus a subtler connection with the temporal changes in a place. An interviewee who had many years of experience with scrumping and who lived in an area abundant with abandoned trees talked about becoming so finely aware of the natural processes that he "watched for when the bees start to fly" (Karl), since the first step toward a fruit tree bearing fruit is the pollination by bees. Another noted how "you get into the mindset of thinking when the fruit will be ripe" (Ola). Another commented on how the experience made him curious:

It's really interesting to watch the fruit trees and wonder is it ripe or unripe. I start to look if the fruit is getting ripe and start thinking about when it might be ready to pick. This year I really looked forward to apple picking time. You find yourself following the trees' development. (Michael)

All of the interviewees noted how the dormant period of winter left a gap, with one commenting how "in winter nothing happens, well it was like that last winter anyway. It's a shame" (Marco). As well as experiencing an appreciation and awareness of the seasonal affect on the fruit trees in terms of the fruit tree's development, interviewees also thought about the life of trees over the long term. They developed an awareness of the history of the tree and an acceptance of a cyclical process repeated every year. For instance, one interviewee noted how "when we come across a tree where fruit was lying on the ground and just rotting then we make sure that we go there a bit earlier the next year" (Karl).

This aspect of timing is often highlighted in the mundraub.org entries, for instance with a note in the tag about when the fruit was ripe: "Harvestable from the end of July (try first). In season until end of September, from October onwards it is a bit of a 
PROPERTY OF MIT PRESS: FOR PROOFREADING AND INDEXING PURPOSES ONLY

risk since there is hardly any fruit left on the tree" (Sunday, July 25, 2010, Dalem). Similar to the relationship with place is the relationship with the seasons, and thus with time. This suggests both a heightened awareness of the embeddedness of the tree's development (and thus usefulness) in time and also on a wider level-in the history or environmental changes in the place and the connection between this change and the tree's placement in the landscape.

\section{Appreciation and Regard}

All of the interviewees expressed the perception that it was just a shame not to collect fallen fruit and make use of it. For example, several people echoed this prevalent feeling by saying, "I just think it's a shame when good fruit just drops off the tree and it isn't used" (Ola), and "there is so much delicious fruit that grows near us and that no one uses" (Marco), and "for so long it has just been there for the birds" (Michael). This experience was described in the same way by city dwellers and town residents as by those who lived in the countryside. One interviewee described his experience with a pear tree in his own garden: "We went away for a week and by the time we got back the fruit was no good-I was a bit annoyed" (Michael). In fact, the frustration at seeing "unused" trees was often most strongly described by those who lived or had links to the country, where there were many "abandoned" trees or orchards in which they perceived the fruit was going to waste. One interviewee (Michael) described his visit to his parents' village where "there are lots of fruit trees which are hardly ever picked, and then I noticed in my parents' fridge that the apples come from the supermarket." This reporting of "unused" fruit (i.e., fruit "on offer" but not being taken) shows how the relation of regard between the tree and the person suggests that not harvesting the fruit would be in some way disrespectful. The idiom that an older interviewee who lived in a small town close to the country where lots of fruit trees were abandoned recounted was that "what grows has worth" (Karl). Karl talked about how he and his wife "were given a field pretty much as a gift by the owner, not the field itself, but the fruit in it." The trees, through their gift of fruit, can be seen as creating an obligation to reciprocate (Offer 1997, 455). All the participants expressed some obligation to harvest the fruit, and that by doing so they felt rewarded in a manner totally outside of monetary value. In fact, people went out of their way to emphasize that they didn't scrump for financial reasons. Yet scrumping did not, in most cases, replace or substitute the mundraub.org users' consumption of fruit from shops. They still reported buying fruit during winter, but with a different awareness of the fruit as product; some recounted that they subsequently only bought fruit grown in Germany, or choose certain older varieties of apple. Thus scrumping was not viewed as an economic activity, but was driven by a compulsion to reciprocate and accept the gift that the tree was offering, where the value was still embedded within the context of the particular tree or orchard where the fruit was harvested. 
PROPERTY OF MIT PRESS: FOR PROOFREADING AND INDEXING PURPOSES ONLY

\section{Sharing}

The need to harvest "unused" or "forgotten" trees sometimes meant that people gathered much more than they could practically consume, and therefore they had to consider how to store, preserve, and prepare the fruit. In this sense the harvesting of the fruit became a point of negotiation with a wider social group. It opened up the process of gathering the fruit to a possibility of sharing what had been harvested. This happened on many levels: first, there was the sharing of knowledge and experience; second, the literal sharing or offering of surplus fruit; third, the sharing of recipes and modes of preserving or preparing fruit; and finally, the possibility of literally sharing the act of harvesting the fruit. Since the mundraub.org site is anonymous and provides only map-based tagged information, the Facebook site and links within a person's own social community became the framework through which this sharing or exchanging practice was enacted. Sharing place-based information can be a rich social practice and serve as the basis for creating a sense of communal co-presence (Willis et al. 2009). Interestingly though, there is no social network structured around mundraub.org usage. Although there is a large number of members on the Facebook group there is little differentiation between members and no explicit links between friends. When people tried to establish these social links, they reported how they been unsuccessful. For instance, one interviewee, who lived in a large city, described how he put a message on Facebook asking if anyone wanted to come and pick damsons because "there was a space in the car and it seemed a shame not to share. But no one replied. I don't know why" (Ola).

On the Facebook site one interviewee posted the message "who will take some of my quinces?" (Danielle), which resulted in two replies, one being "if you had plums I'd happily help" and the other being "Frankfurt is just too far for me." None of the interviewees reported using the Facebook site in conjunction with their existing social networks as an alternative marketplace. Thus their motivation to share was thwarted by the geographical distribution of the Mundraub members on the Facebook site and a lack of interest or engagement with an alternative place of exchange in their own local social network.

This suggests a very different approach to foraging and hunting as a practice, since although there was a motivation to share individual finds with a wider group there was actually no demand for this. In terms of understanding how scrumping through mundraub.org is constructed as an non-market exchange, it is important to note that it does not operate through the commonly accepted model of the benefit of communal sharing or through the joint exploitation of a resource, as is often practiced in foraging (Offer 1997, 457). Neither does it specifically support a regional or localized approach to the fruit: there are no regional subgroups of members and knowledge about fruit identification, and preparation is not region-specific. In this sense the Facebook site, 
PROPERTY OF MIT PRESS: FOR PROOFREADING AND INDEXING PURPOSES ONLY

although constructing some form of social structure for sharing local knowledge, does not actually allow for this knowledge to be re-embedded locally since the site itself is globally accessible.

\section{Harvesting}

The main encounters that participants had at a social level occurred at the point when they picked the fruit. Here many reported funny stories about the public perception when they started to harvest fruit trees. This was closely tied in with the negotiation of the "ownership" of the tree. The process of observing a suitable tree and then trying to find out who owned it-either an individual or a local body-and if it was a "forgotten" tree became one in which all Mundraubers necessarily became involved. Many chose to literally avoid people and human contact when harvesting a tree to avoid confronting any issues about ownership. For example: "I used to just see a tree and when I had time and there was nobody about or thought that the tree didn't belong to anybody I just picked the fruit. But now I am much more prepared-I find out first and then pick" (Marco). The practical aspect of trying to ascertain the ownership of the tree is documented in many of the mundraub.org website tags. A large proportion of the tags make some reference to ownership. Some describe this based on local knowledge of the trees or orchards and some based on observation of whether the tree was within some form of boundary such as a fence. Yet one interviewee highlighted an awareness of the fine line that scrumping walks between legal and illegal activity when he stated, "We are a little but like thieves" (Karl). Others described how created an audience when they did pick fruit in a place with passersby. One city dweller described an unintentional "public performance":

A highlight this year was to discover a damson tree at the U-Bahn [underground or metro] station just round the corner from where I live. When I picked the fruit I used an apple picker, which you really need in the city, and I got quite an audience with people watching me who were really quite surprised about what I was doing. I ended up answering lots of questions mainly from old ladies, but generally most people were very shy and reserved about the whole thing. (Michael)

Another described a confrontation he had while picking a tree in the city:

People's reactions when they see you picking a tree can be really varied. Most seem quite interested and ask what you are doing and whether you can eat the fruit. But I had another situation last summer. I harvested a branch with Amelanchier [shadbush] berries in a residential street. It was next to a furniture shop and the owner came out and was really interested. I let her try a few berries and she then went independently and looked on the Internet to see what sort of berries they were. From the same building an old lady appeared and complained bitterly that I had picked "the beautiful berries" from the tree, and that it looked ugly without them, and that I should seriously consider if that's what I should be doing. I offered her the berries to try but all she was interested in was what they looked like. (Sebastian) 
Despite the different contexts for the trees-the single tree in the urban setting, the extra-urban orchard or the line of trees along a country road-the negotiation of ownership at the point of harvesting and the confrontation between people with different understandings of the use of trees were common experiences to all interviewed. This demonstrates that the perception is not differentiated between the urban or rural context, but more by a sense of people paying attention and valuing the resource within the locality. For instance, a participant described how "one day, we started harvesting some cherry trees. And some of the people living or working nearby were really stunned because they had never realized that there were real cherry trees. One lady said: I have been working here for thirty years, and I've never noticed this cherry tree that grows directly in front of the shop door" (Kai). The "noticing" or paying attention to the tree was something that was undertaken by the Mundraubers. Other locals were either simply not aware of the tree or had a different perception of it, such as a visual appreciation of the berries, but not as a source of fruit for consumption. At the point when the Mundrauber "paid attention" to the tree while harvesting it, the tree was transformed in terms of how it was perceived. It became a site of discussion; a meeting of these different perspectives, and sometimes a confrontation where different value sets were applied.

\section{Defining Local}

The final aspect of our findings was the way in which a tree was defined as being local to the interviewees. This occurred on two levels; first they described a certain distance from their home that was local. All the interviewees described this as being "about five kilometers." A rough check of participants' tags in relation to the area in which they live confirms this.

The locality of the tree was not literally on their doorstep but it was located within a circle of about a five kilometer radius, which extended to, and tended to coincide with, the land that lay on the edge or just beyond the perimeter of the village, town, or city in which they lived-see figure 9.3. "Local" was also defined through the quality of the fruit. In the study of the tags for the website a large number gave some description of the visual appearance and taste of the fruit. For instance: "The pear is small and very juicy, crunchy and sweet," or "tangy-sour, but still good to eat without having to pull a face :-)." Another interviewee described how he had taken the initiative to bring the fruit into his children's kindergarten "just to let them know about what fruit was growing nearby and let them see 'real' fruit" (Michael). Another pointed out how wild fruit is more distinctive in several respects:

Apples from wild trees just look different. Gala apples always taste the same. It doesn't matter when or where you buy them. They look the same too. But on wild trees the apples tend to all look different; they're not perfect for a start. Also wild fruit trees tend to be a whole range of apple varieties." (Marco) 

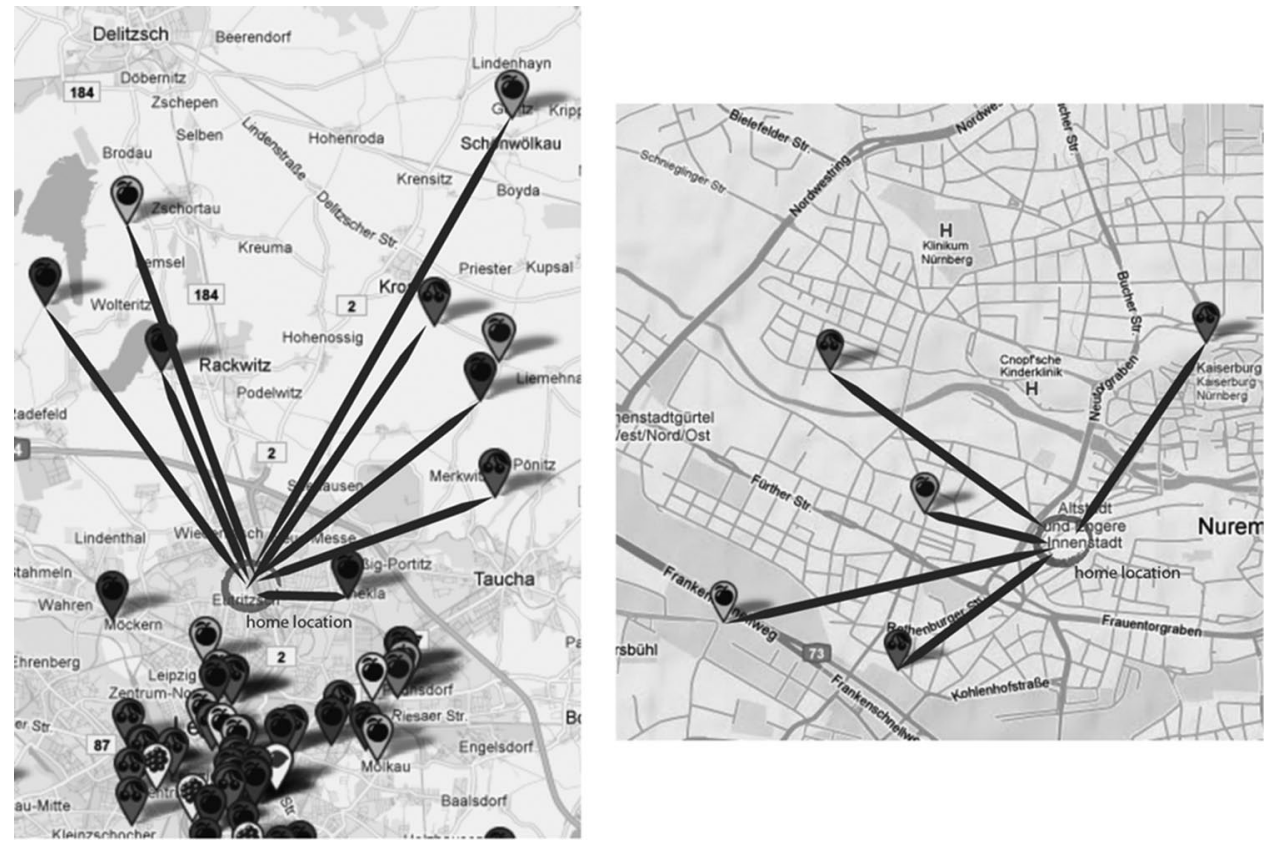

Figure 9.3

Fruit tree tags and the distance relationship to two Mundraubers.

Thus, "local" in this sense was a much more differentiated experience of the fruit. Each tree and location had specific characteristics, which were only definable through the direct experience of tasting the fruit; most would find a tree and pick the fruit and try it for taste. In fact, despite their interest in their local trees and the quality of the fruit, only one interviewee felt able to define himself as an expert on apple varieties or identifying fruit. Indeed, one interviewee who had also scrumped for many years, even before using mundraub.org, claimed to know only three or four fruit varieties by name and sight. Instead, he knew and remembered individual trees and orchards and what the fruit tasted like and its particular usefulness: "One type you have to eat pretty much straight after picking, another we can keep until February" (Karl).

Interestingly, a number of interviewees set the context of their scrumping activities not just in terms of where they currently lived but also in relation to the place where they had grown up. Some had made entries in both locations, and one commented: "I also found trees in the village where I grew up," whereas another described how she had "grown up in the country and my parents and grandparents had fruit trees."

A final way in which locality was defined was through the description of the tree in the tags on the website. Rather than simply describing the physical location and 
how to find the tree, the people often posted some context for how the tree came to be there in the first place. Some conducted a "fruit tour" by tracing the route to the tree through other places, for example, "an old apple avenue in the middle of some fields ... whatever you don't like just give to the horses in the opposite field; nearby on the 'Apothecary-hill' there is a viewing tower with a great view of the surroundings." Others describe the history of the place and why the fruit trees are now abandoned such as many "fruit tree meadows." ${ }^{3}$ Another entry noted, "On the way [are] lots of apple and pear trees as well as plum, cherry, and quince trees. These are what are left over from a village that became victim to the mining industry." In this way locality was not just defined as a geographic territory or boundary but as a set of tastes and appearances of certain fruit or a sense of the spatial locality as history.

\section{Discussion: Embedded Relationships with Food and Place}

The key characteristic of mundraub.org use was that it documented an embedding of a relationship between people and place. If we return to Offer's concept of "regard," this can suggest an approach to understanding the nature of this embedded relationship. Offer (1997) refers to the grant of attention, motivated by the mutual benefit conferred by the process of sharing. This can also be extended to the way in which all of the interviewees in the study described their experience as being about gaining a new "regard" for the place through the attention paid to it in the scrumping activity, and particularly an awareness of the locality and seasonality. Offer explains this type of exchange as a "process benefit," usually in the form of a personal relationship (1997, 251). This was most clearly highlighted in the shared motivation of not wanting to waste good fruit, but also more indirectly in the changed perception of time and seasons at a local level. Through the attention paid to the trees the Mundraubers became sensitized to the temporality of local fruit; there was a palpable expectancy that spring would bring a new year of fruit and that certain trees were ripe at certain times. This was recognized as valuable by the interviewees and was seen as something gifted to them in the process of exchange between tree, locale, and the harvesting of fruit. There was a heightened sensitivity also reflected in the way that individual trees were understood as having fruit that had distinctive characteristics and properties. This direct experience of the tree was literally negotiated through taste. In this way such food products become embedded through a process of mobilization of values and meanings that construct a place as the "local." According to Roberta Sonnino (2007, n.p.) this localization process is about creating a discourse that "roots this product in time and space." This concept of embeddedness is highlighted by Ash Amin, who states that, "the local emerges primarily as a 'relational space,' a space of interrelated scales and interdependent subjects where the social, economic, political and cultural inside and outside are constituted through the topologies of actor networks" (Amin 
PROPERTY OF MIT PRESS: FOR PROOFREADING AND INDEXING PURPOSES ONLY

2004, 33). The link, acknowledged by both interviewees and in some tags, between the tree and the history of the place or the birthplace, reinforces the embedded nature of the relationship with the tree, not just in the current time, but also in the past history of the place.

Mundraub.org also created a new granting of attention and exchange to forgotten, in-between, and non-places as valuable sites and possible places of consumption and exchange. This involved recognizing a whole range of sites as sources of fruit: trees along the side of roads, in car parks, and in the middle of urban sites not typically viewed as "natural." This also included a number of links to abandoned and underused places, which through the location of productive fruit trees were not perceived as derelict or "broken" but as sites of growth and difference (Franck and Stevens 2006). The discovery of fruit trees in city-center locations was an important aspect to city dwellers; a Berlin resident commented, "Before Mundraub I didn't realize that there were openly accessible fruit trees right in the middle of the city. I appreciate Berlin all the more now because of this. I look much more carefully at the trees in parks and in the streets" (Simone). Other interviewees described how they started to reassess the functionality and value of locations previously regarded as non-places, such as transport hubs and car parks. For example, one noted, "Sometimes they're in places you'd never expect-like car parks. You make use of the place so much more" (Michael). Thus the attention to the local in this sense was a place around which a person could construct meaning, since it was not regarded as being owned or within an existing community's territory. In this way local eating can be understood as being embedded in small-scale, highly differentiated spaces that have specific qualities and territories. This is in stark contrast to the homogenized global spaces of fast food takeaways and chain supermarkets. By reinstating small and disregarded sites as locations of value, opportunities for a new sense of relatedness in urban space were opened up.

\section{Summary}

We discussed how changing ideas of locality and place in relationship to food affect an understanding of the production and consumption of food. In this context, the "re-placing" of food can be seen not just as reconstructing relationships between consumer and producer, but as a way of people re-embedding their relationship with food through a sense of locality. In our case study of a scrumping Web platform in Germany, we explored how this locality is constructed through four perceptions: a simple awareness of trees in the environment; a changing sense of time and seasons; the exchange created through picking fruit; and a refined sense of what local meant in spatial terms. These changing relationships with place were enacted through a "regard" for, or by paying of attention to, the tree and the place, and with a reciprocal exchange that created a sense of embeddedness. 
PROPERTY OF MIT PRESS: FOR PROOFREADING AND INDEXING PURPOSES ONLY

\section{Acknowledgments}

We would like to thank the interviewees that participated in our study: Michael, Sebastian, Marco, Ola, Simone, Karl, Danielle, and Niko. Thank you also to the Daniel Nielsen and Kai Gildhorn from mundraub.org.

\section{CINNAMON PLUMS}

The stewed plums can be served with pancakes, vanilla ice cream, or rice pudding. If stored in a cool, dark place or in a refrigerator it will keep for a few months.

\section{Ingredients}

$2^{1 / 4} \mathrm{lbs}$. ripe plums or damsons

1 cup water (or alternatively, red wine)

$13 / 4$ oz. caster sugar (known as "baker's sugar" in the US, it is more finely granulated than table sugar but not as fine as powdered sugar)

2-4 cinnamon sticks (ideally large cinnamon sticks, which are slightly more bitter and tangy than the smaller ones)

\section{Preparation}

1. Wash the plums or damsons, halve them, and remove the stones. Place the fruit in a large wide, heavy-based saucepan with the water, sugar, and cinnamon sticks. Cover and bring to a boil.

2. Cook gently over a low heat, trying to avoid stirring the fruit. Once the fruit is tender but not falling apart, remove the pan from the heat.

3. While the fruit is cooking, sterilize preserving jars and lids by boiling them in water. Ladle the hot stewed fruit into the hot jars, cover with the lids, and carefully turn them upside down. Wipe any spillages with a clean damp cloth and leave the jars to cool completely.

\section{Notes}

1. See http://de.wikipedia.org/wiki/Mundraub.

2. Scrumping has a slightly different cultural connotation. The practice of "Mundraub" is legally considered theft if the owner is not asked for permission beforehand, but it is seen generally as an opportunistic and publicly acceptable activity. 
PROPERTY OF MIT PRESS: FOR PROOFREADING AND INDEXING PURPOSES ONLY

3. The German term is Streuobstwiese, which refers to a traditional type of grassland-orchard management system consisting of a meadow with scattered fruit trees. They have now become rare; over 70 percent of meadows were lost between 1965 and 2000.

\section{References}

Allen, Patricia. 2004. Together at the table: Sustainability and sustenance in the American agri-food system. Philadephia: Pennsylvania State University Press.

Amin, Ash. 2004. Regions unbound: towards a new politics of place. Geografiska Annaler 86B:33-44.

Brauchle, Alfred. 1935. Was ist der naturheilkunde? Der Naturarzt 63:153-156.

Duram, Leslie, and Lydia Oberholtzer. 2010. A geographic approach to examining place and natural resource use in local food systems. Renewable Agriculture and Food Systems 25 (2):99-108.

Franck, Karen, and Quentin Stevens. 2006. Loose space. London: Routledge.

Friedmann, Harriet. 1993. After Midas's feast: Alternative food regimes for the future. In Food for the future: Conditions and contradictions of sustainability, ed. Patricia Allen, 213-233. New York: Wiley.

Frosch, Katharina. 2012. Mundraub? allmendeobst! In für eine neue politik jenseits von markt und staat, ed. Silke Helfrich, 273-275. Bielefeld: Transcript Verlag.

Hendrickson, Mary, and William Heffernan. 2002. Opening spaces through relocalization: Locating potential resistance in the weaknesses of the global food system. Sociologia Ruralis 42:347-369.

Hinrichs, Clare. 2000. Embeddedness and local food systems: Notes on two types of direct agricultural market. Journal of Rural Studies 16:295-303.

Ilbery, Brian, and Moya Kneafsey. 2000. Registering regional speciality food and drink products in the UK: The case of PDO's and PGI's. Area 32 (3):317-325.

Kindermann, Arndt. 1997. Okologische chancen und perspektiven von regionalproduktion und regionalvermarktung. Naturschutzbund Deutschland e.V. Bonn: NABU.

Krug, Leopold. 1808. Geschichte der staatswirthschaftlichen Gesetzgebung im preußischen Staate: von den ältesten Zeiten bis zu dem Ausbruch des Kriegs im Jahre 1806, Band 1, Berlin.

Latour, Bruno. 1987. Science in action. How to follow scientists and engineers through society. Cambridge: Harvard University Press.

Lyson, Thomas, and Judy Green. 1999. The agricultural marketscape: A framework for sustaining agriculture and communities in the northeast US. Journal of Sustainable Agriculture 15 (2/3): 133-150. 
PROPERTY OF MIT PRESS: FOR PROOFREADING AND INDEXING PURPOSES ONLY

Offer, Avner. 1997. Between the gift and the market: The economy of regard. Economic History Review 50 (3):450-476.

Oltersdorf, Ulrich, and Kurt Gedrich, eds. 2001. Ernährungsziele unserer Gesellschaft: Die Beiträge der Ernährungsverhaltens-Wissenschaft. Berichte der Bundesforschungsanstalt für Ernährung, Karlsruhe. Dokumentation zur 22. Bonn: AGEV-Jahrestagung.

Paxton, Angela. 1994. The food miles report: The dangers of long-distance food transport. London: SAFE Alliance. http://www.sustainweb.org/publications/?Id=191.

Sonnino, Roberta. 2007. The power of place: Embeddedness and local food systems in Italy and the UK. The Anthropology of Food S2 (March). Available at: http://aof.revues.org/index454.html.

Willis, Katharine, Kenton O'Hara, Thierry Giles, and Mike Marienek. 2009. Sharing knowledge about places as community building. In Shared encounters, ed. Katharine Willis, Konstantinos Chorianopoulos, Mirjam Struppek, and George Roussos, 291-308. New York: Springer.

ZMP. 2003. Nahrungsmittel aus der Region—Regionale Spezialitäten. Bonn: ZMP. 